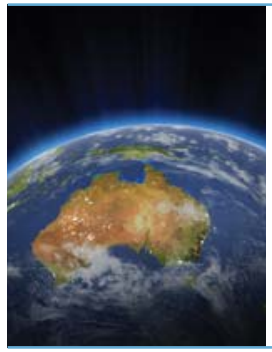

\title{
Global opportunities and obligations for Australian general practice
}

\author{
How can Australian general practice support strengthening primary care to \\ achieve universal health coverage in the rest of the world?
}

Michael R Kidd AM, MD, FRACGP Executive Dean

Faculty of Medicine, Nursing and Health Sciences, Flinders University, Adelaide, SA.

michael.kidd@ flinders.edu.au

doi: $10.5694 / \mathrm{mjal} 4.00787$

Online first 30/06/14 $\mathrm{n}$ a changing global health landscape, Australian general practitioners have an opportunity to make positive contributions, both individually and collectively, towards primary care reforms underway in other countries.

Many nations are facing similar health challenges to those in Australia: rising health care costs; unsustainable expenditure on hospital care; an ageing population; rising rates of obesity, non-communicable diseases and mental health problems; and community expectations about health care access, quality and pricing. We have an obligation as part of our commitment to humanity to share our experiences and our solutions to tackling the world's greatest health problems. The opportunity to share our knowledge and expertise can also provide insights to support improvements in our own health system. We often concentrate on local concerns affecting general practice, and the recent federal Budget has focused attention sharply on local challenges for clinical services, education and training in general practice. However, many governments and colleagues elsewhere in the world are examining how our GPs are working with patients and communities to increase life expectancy, support vulnerable populations and achieve equitable outcomes.

The focus of the World Health Organization is now firmly on universal health coverage, to "ensure that all people obtain the health services they need without suffering financial hardship when paying for them". ${ }^{1} \mathrm{WHO}$ DirectorGeneral Dr Margaret Chan recently described universal health coverage as

the single most powerful concept that public health has to offer ... the best way to cement the health gains made during the previous decade. It is a powerful social equalizer and the ultimate expression of fairness. ${ }^{2}$

In December 2012, a United Nations resolution was passed "encouraging governments to move towards providing universal access to affordable and quality health care services". ${ }^{3}$ Common challenges are emerging in ensuring strong, efficient health systems with sufficient numbers of well trained and motivated health workers. ${ }^{3}$ As governments around the world tackle universal health coverage, many see family medicine as part of the solution and regard Australia as having an enviable model of primary care. This is based on strong general practice, providing universal health care access to our population, and having lessons to share about training a highly skilled general practice workforce to meet the needs of urban, rural and remote communities.

The Royal Australian College of General Practitioners (RACGP) has a strong history of supporting the development of family medicine in other Asia-Pacific nations, especially Malaysia, Singapore, Hong Kong and Fiji. It also has longstanding recognition and respect as a global leader in the development of postgraduate training in general practice, standards for general practices ${ }^{4}$ and guidelines on preventive health and chronic disease management. ${ }^{5}$

Providing a rural workforce of skilled health professionals is an urgent need for many nations. The Australian College of Rural and Remote Medicine, ${ }^{6}$ the RACGP7 and the Remote Vocational Training Scheme ${ }^{8}$ have developed valuable resources to support rural general practice and the training of rural doctors. Our regional general practice training providers have established links to provide support for training and curriculum development in other countries. Many individual Australian GPs have strong cultural understanding and knowledge of countries in our region, especially our closest neighbours such as Papua New Guinea, Timor-Leste, Indonesia and island nations of the western Pacific. These GPs are working alongside their peers in these areas to assist them to deliver universal health coverage, based on strong primary care, for the people of their nations.

Australian governments also have a strong track record of supporting health care programs in many Asia-Pacific countries. While targeted vertical public health programs are important, we would do well to refocus more of our international aid efforts towards supporting nations to strengthen their systems of primary care.

Australia can also, of course, learn from other nations. The primary care reforms underway in populous nations like Brazil and China will provide new knowledge and experience. The governments of these countries see communitybased health teams led by family doctors as an important part of their ambition to achieve universal health coverage for their populations. Brazil's model of 33000 family health teams is regarded as a global success in universal health coverage, yet the government of Brazil is looking to Australia for advice on ways to train and support a strong rural medical workforce. ${ }^{9,10}$ With 800 million people living in rural areas, the government of China recognises that one of its biggest challenges is training the family doctor workforce to meet the needs of the nation. If these problems 
can be overcome, especially in rural areas, it will provide lessons that will flow to many other parts of the world facing the same challenge of providing universal health coverage. ${ }^{11,12}$ There is an opportunity for Australian general practice to work alongside our colleagues in Brazil, China and elsewhere as part of these global reforms.

Competing interests: I am president of the World Organization of Family Doctors (WONCA) and a past president of the RACGP.

Provenance: Commissioned; externally peer reviewed.

1 World Health Organization. What is universal health coverage? http:// www.who.int/features/qa/universal_health_coverage/en (accessed May 2014)

2 World Health Organization. Health research is essential for progress towards universal health coverage [media release]. 15 Aug 2013. http:// www.who.int/mediacentre/news/releases/2013/world_health_ report_20130815/en (accessed May 2014).

3 World Health Organization. Research for universal health coverage: world health report 2013. Geneva: WHO, 2013. http://www.who.int/whr/2013/ report/en (accessed May 2014).

4 Royal Australian College of General Practitioners. Standards for general practices. 4th ed. Melbourne: RACGP, 2010. http://www.racgp.org.au/yourpractice/standards/standards4thedition (accessed May 2014).
5 Royal Australian College of General Practitioners. Guidelines for preventive activities in general practice. 8th ed. Melbourne: RACGP, 2012. http://www. racgp.org.au/your-practice/guidelines/redbook (accessed May 2014).

6 Australian College of Rural and Remote Medicine. ACRRM primary curriculum. 4th ed. Brisbane: ACRRM, 2013. http://www.acrrm.org.au/misc/ curriculum/Default.htm (accessed May 2014).

7 Royal Australian College of General Practitioners. Fellowship in Advanced Rural General Practice. http://www.racgp.org.au/education/fellowship/ fellowship-in-advanced-rural-general-practice (accessed May 2014).

8 Remote Vocational Training Scheme [website]. http://www.rvts.org.au (accessed May 2014).

9 Mendonca CS. The Brazilian Unified Health System: primary health care in action. In: Kidd MR, editor. The contribution of family medicine to improving health systems. Oxford: Radcliffe Publishing, 2013.

10 Kidd MR. From the President: the world of rural family medicine. World Organization of Family Doctors News, May 2014. http://www. globalfamilydoctor.com/News/FromthePresidenttheworldofruralfamilym edicine.aspx (accessed May 2014).

11 Bowen C, Yanmin D, Aimin G, Delu Y. Promoting universal primary health services in China through general practice reforms. In: Kidd MR, editor. The contribution of family medicine to improving health systems. Oxford: Radcliffe Publishing, 2013.

12 Kidd MR. From the President: China and the rise of the family doctor. World Organization of Family Doctors News, April 2014. http://www. globalfamilydoctor.com/News/FromthePresidentChinaandtheriseofthefa milydoctor.aspx (accessed May 2014). 